\title{
Collisionally Activated Dissociation of Protonated 2'-Deoxycytidine, 2'-Deoxyuridine, and their Oxidatively Damaged Derivatives
}

\author{
Huachuan Cao and Yinsheng Wang \\ Department of Chemistry, University of California, Riverside, California, USA
}

\begin{abstract}
We examined the collisionally activated dissociation (CAD) pathways of protonated 2'-deoxycytidine (dC), 5-formyl-2'-deoxycytidine (5-FmdC), 5-hydroxy-2'-deoxycytidine (5-OHdC), 5-hydroxymethyl-2'-deoxycytidine (5-HmdC), and their corresponding stable isotope-labeled compounds to gain insights into the effects of modifications on the fragmentation pathways of the pyrimidine bases. Multi-stage MS $\left(\mathrm{MS}^{\mathrm{n}}\right)$ results showed that protonated cytosine, its 5-hydroxyland 5-hydroxymethyl-substituted derivatives, but not its 5-formyl-substituted analog, could undergo Dimroth-like rearrangement in the gas-phase. The elimination of HNCO was one of the major fragmentation pathways observed for the protonated ions of all $\mathrm{dC}$ derivatives except for 5-hydroxymethylcytosine, which underwent this loss only after a $\mathrm{H}_{2} \mathrm{O}$ molecule had been eliminated. In addition, the protonated cytosine and 5-hydroxycytosine can undergo a facile elimination of $\mathrm{NH}_{3}$ molecule. This loss, however, was not observed for protonated 5-hydroxymethylcytosine, 5-formylcytosine, and their uracil analogs. Taken together, our study demonstrated that modifications could alter markedly the CAD patterns of the protonated pyrimidine bases. The results from this study provided a basis for the identifications of other modified pyrimidine bases/nucleosides by tandem mass spectrometry. (J Am Soc Mass Spectrom 2006, 17, 1335-1341) (c) 2006 American Society for Mass Spectrometry
\end{abstract}

M odified nucleosides in mammalian cells may arise from posttranscriptional modifications of RNA [1] and oxidative damage of nucleic acids [2, 3]. In this respect, more than 100 different types of modified ribonucleosides have been found [1], and many of them play a pivotal role in the structural stability of ribosome and the function of tRNA [4-6]. On the other hand, more than 30 single-nucleobase lesions have been shown to be induced by both endogenously and exogenously generated reactive oxygen species (ROS) [7]. Such DNA damage products, if not repaired promptly, may lead to pathological consequences including cancer and aging $[8,9]$.

As a result of metabolic disorders, many modified nucleosides, which are degradation products from impaired RNA or DNA, are found in urine or other body fluids in abnormal amounts. It has been suggested that these modified nucleosides in body fluids may serve as biomarkers for various diseases [10-12] and oxidative stress $[13,14]$. Mass spectrometry may offer an accurate and sensitive means for the identification and quantifi-

\footnotetext{
Published online July 26, 2006

This paper is in honor of Professor James A. McCloskey, who was the recipient for the 2005 Award for a Distinguished Contribution in Mass Spectrometry.

Address reprint requests to Dr. Y. Wang, Department of Chemistry, University of California, Riverside, CA 92521-0403, USA. E-mail: yinsheng.wang@ucr.edu
}

cation of modified nucleosides, especially when coupled to gas or liquid chromatography (GC or LC) [15, 16]. For such studies, it is often important to understand the fragmentation pathways of those modified and natural nucleosides/nucleobases.

Although the collisionally activated dissociation (CAD) studies of adenine, guanine, and uracil have been published previously [17-19], up to now there is no report on the systematic study on the fragmentations of protonated cytosine, especially for stable isotope-incorporated cytosine. Herein we examined the dissociations of protonated cytosine and its oxidatively damaged derivatives. Our goal was to understand the fragmentation pathways of the protonated ions of these nucleobases and to examine the effect of modifications on the fragmentation. For comparison, we also investigated the CAD of the corresponding oxidatively modified derivatives of uracil. The outcome of the study may help to build a basis for the study of pyrimidine biosynthesis and metabolism as well as for the characterization of the structures of novel modified pyrimidine bases/nucleosides by MS/MS.

\section{Experimental}

\section{Materials and Synthesis}

Urea- ${ }^{15} \mathrm{~N}_{2}\left(99.8 \%{ }^{15} \mathrm{~N}\right.$ enriched) was obtained from Cambridge Isotope Laboratories (Andover, MA). 2'- 


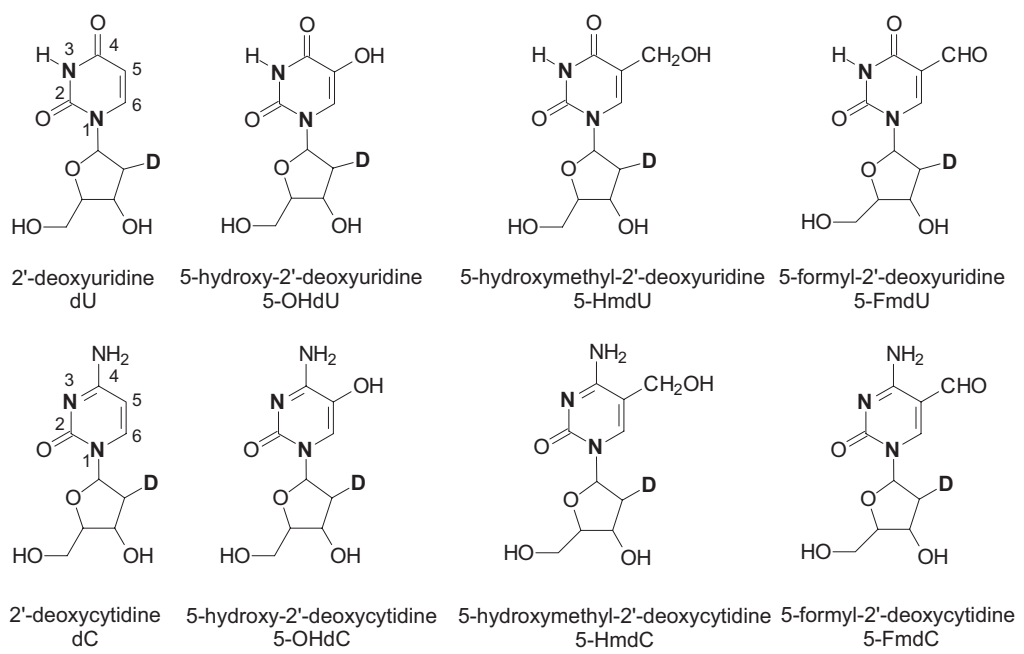

Scheme 1

Deoxyuridine $(\mathrm{dU})$ and 2'-deoxycytidine $(\mathrm{dC})$ were purchased from Berry and Associates (Ann Arbor, MI), and tributyltin deuteride and 5-hydroxymethyl-2'-deoxyuridine $(5-\mathrm{HmdU})$ were obtained from Sigma-Aldrich (St. Louis, MO). All other chemicals were obtained from Aldrich or VWR International (West Chester, PA). Modified nucleosides 5-formyl-2'-deoxyuridine (5-FmdU), 5-hydroxy-2'-deoxyuridine (5OHdU), 5-formyl-2'-deoxycytidine (5-FmdC), 5-hydroxy-2'-deoxycytidine (5-OHdC), 5-hydroxymethyl$2^{\prime}$-deoxycytidine (5-HmdC), and all the isotopicallylabeled nucleosides (Scheme 1) were synthesized according to published procedures [20,21]. The purity and identity of the synthesized compounds were verified by HPLC, NMR, and mass spectrometry.

\section{ESI-MS}

ESI-MS experiments were carried out on an LCQ Deca XP ion-trap mass spectrometer (ThermoFinnigan, San Jose, CA). Nucleoside $\mathrm{dC}$ and its derivatives were prepared in a $20-\mu \mathrm{M}$ aqueous solution containing $50 \%$ methanol and $1 \%$ formic acid. Similar solutions were prepared for $\mathrm{dU}$ and its derivatives except that the concentrations were $30 \mu \mathrm{M}$. The solution was infused directly into mass spectrometer with a syringe pump at a flow rate of $3.0 \mu \mathrm{L} / \mathrm{min}$. The spectra were recorded in the positive-ion mode. The spray voltage was $4.5 \mathrm{kV}$, and the temperature for the heated capillary was maintained at $225^{\circ} \mathrm{C}$. The automated gain control (AGC) feature was employed, and the maximum numbers of ions were set at $5 \times 10^{7}$ and $4 \times 10^{7}$ in MS and $\mathrm{MS}^{\mathrm{n}}$ modes, respectively. The normalized collisional energy was optimized (15-38\%) so that the precursor ion was clearly present $(10-40 \%)$, but not the most abundant ion in the product-ion spectrum. Isolation width was set at 3 and $2 \mathrm{~m} / z$ units for MS/MS and MS ${ }^{n}$, respectively. To obtain the product-ion spectra for low-mass precursor ions, the activation $\mathrm{Q}$ was increased slightly (in a range of $0.25-0.33$ ) to minimize the loss of fragment ions.

\section{Results and Discussion}

We took advantage of the multi-stage MS capability of the ion-trap mass spectrometer and the availability of stable isotope-incorporated nucleosides to elucidate the fragmentation pathways of $\mathrm{dC}, \mathrm{dU}$, and their oxida-

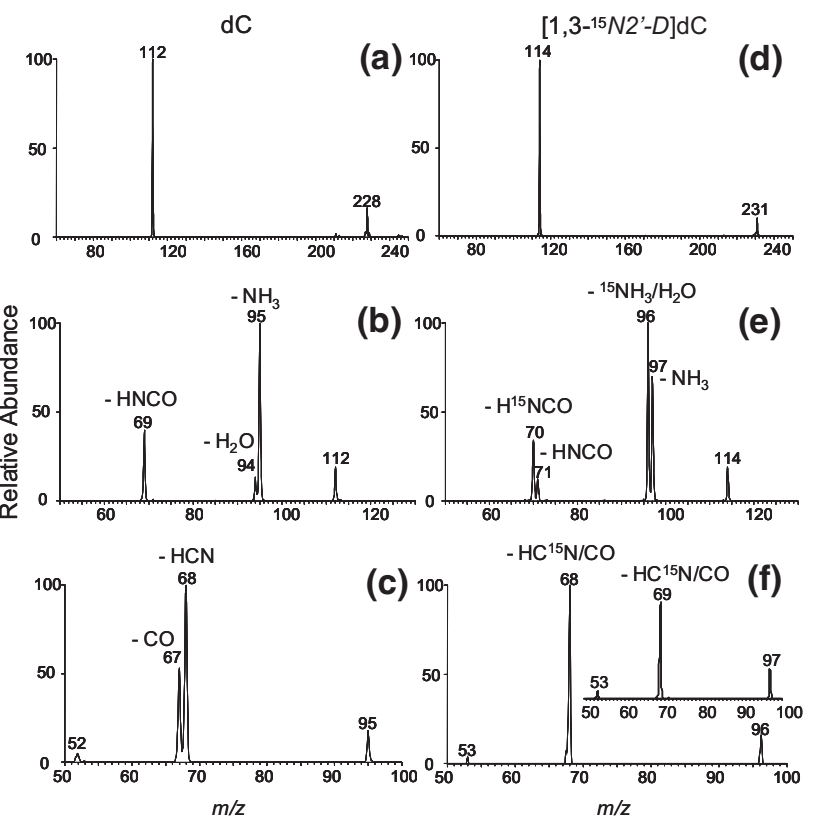

Figure 1. Mass spectra of $\mathrm{dC}$ (left) and $\left[1,3-{ }^{15} \mathrm{~N}, 2^{\prime}-\mathrm{D}\right] \mathrm{dC}$ (right): Product-ion spectra of the $[\mathrm{M}+\mathrm{H}]^{+}$ions of $\mathrm{dC}(\mathbf{a})$ and $\left[1,3-{ }^{15} \mathrm{~N}\right]$ $\mathrm{dC}$ (d); product-ion spectra of the ions of $\mathrm{m} / \mathrm{z} 112$ and $114\left(\mathrm{MS}^{3}\right)$ observed in (a) and (d) are shown in (b) and (e), respectively; product-ion spectra of the ions of $m / z 95$ and $96\left(\mathrm{MS}^{4}\right)$ observed in (b) and (e) are shown in (c) and (f), respectively. Product-ion spectrum of the ion of $\mathrm{m} / \mathrm{z} 97\left(\mathrm{MS}^{5}\right)$ found in (e) is shown as an inset in (f). 
(a)

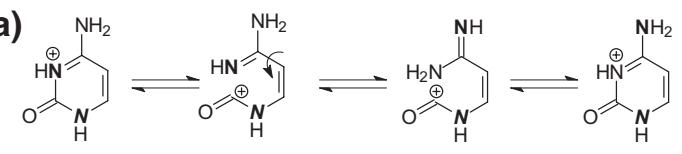

(b)

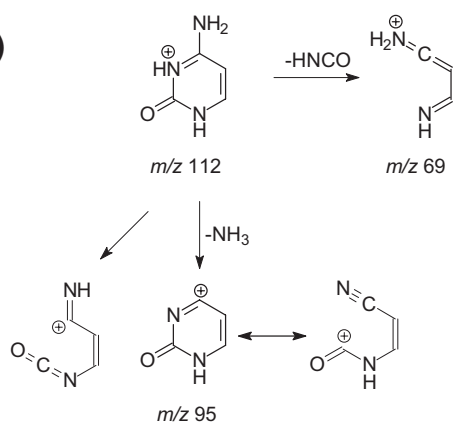

Scheme 2

tively damaged derivatives. This allowed for the unambiguous determination of the origins of many neutralloss fragments and the revelation of new fragmentation pathways. Here we begin with the discussion of $\mathrm{dC}$ and its derivatives.

\section{2'-Deoxycytidine}

Low-energy CAD spectra of the protonated 2'-deoxycytidine and its $\left[1,3-{ }^{15} \mathrm{~N}, 2^{\prime}\right.$-D $]$-labeled analog showed the formation of a dominant product ion corresponding to the $[\mathrm{M}+\mathrm{H}]^{+}$ion of the cytosine (ions of $\mathrm{m} / \mathrm{z} 112$ and $m / z 114$ in Figure 1a and d, respectively). This observation is general for all $\mathrm{dC}$ derivatives studied here.

Further fragmentation of the protonated cytosine (MS/MS/MS or $\mathrm{MS}^{3}$ ) gives rise to two abundant ions of $\mathrm{m} / \mathrm{z} 95$ and 69 , which are attributed to the neutral losses of $\mathrm{NH}_{3}$ and $\mathrm{HNCO}$, respectively, and an ion of $\mathrm{m} / \mathrm{z} 94$ in low abundance, which is due to the neutral loss of a $\mathrm{H}_{2} \mathrm{O}$ molecule. Examination of the product-ion spectrum of the $[\mathrm{M}+\mathrm{H}]^{+}$ion of $\left[1,3{ }^{-15} \mathrm{~N}\right]$ cytosine $\left(\mathrm{MS}^{3}\right)$ revealed four distinct peaks at $m / z 97,96,71$, and 70, which were attributed to the ions formed from the losses of $\mathrm{NH}_{3},{ }^{15} \mathrm{NH}_{3} / \mathrm{H}_{2} \mathrm{O}, \mathrm{HNCO}$, and $\mathrm{H}^{15} \mathrm{NCO}$, respectively. By comparing Figure $1 \mathrm{~b}$ and e, we may conclude that the majority of the ion of $\mathrm{m} / \mathrm{z} 96$ observed in Figure 1e is due the loss of ${ }^{15} \mathrm{NH}_{3}$ from $\left[1,3-{ }^{15} \mathrm{~N}\right]-$ cytosine.

Although there is no systematic study on the fragmentation of cytosine, Nelson and McCloskey [18] reported that, during the fragmentation of protonated uracil, ammonia is primarily eliminated from N3, but not N1, whereas the loss of $\mathrm{HNCO}$, through a retro Diels-Alder (RDA) mechanism, mainly originates from $\mathrm{N} 3, \mathrm{C} 2$, and $\mathrm{O}^{2}$. The loss of HNCO from the $[\mathrm{M}+\mathrm{H}]^{+}$ ion of $\left[1,3-{ }^{15} \mathrm{~N}\right]$ cytosine, however, would require a rearrangement of cytosine component before the elimination. In this context, it is well-known that adenosine can undergo Dimroth rearrangement [22, 23] to exchange the exocyclic $N^{6}$ and endocyclic N1. Theoretical predictions and experimental data unequivocally support that ring cleavage between the N1 nitrogen and C2 carbon followed by rotation about the $\mathrm{C} 4-\mathrm{C} 5$ bond, ring closure, and proton migration constitute the correct pathway for the rearrangement of adenosine [24, 25]. Although there has been no report on the Dimroth rearrangement of unmodified cytosine, $\mathrm{dC}$, or cytidine, the rearrangement of N3-substituted cytosine during acetylation reaction has been observed [26, 27]. Moreover, this type of rearrangement has been employed for the syntheses of ${ }^{15} \mathrm{~N} 3$-labeled uridine [28] and cytidine [29] from the ${ }^{15} \mathrm{~N}^{4}$-substituted cytidine N3-oxide.

We reason that protonated cytosine might undergo a similar rearrangement, which allows for the switching of the N3 and $N^{4}$ nitrogen atoms in the gas phase and facilitates the loss of unlabeled HNCO from $\left[1,3{ }^{-15} \mathrm{~N}\right] \mathrm{cy}-$ tosine (Scheme 2a). In this regard, the protonation of cytosine at N3 site resembles, to some extent, the substitution at N3 site, which results in the weakening of the N3- C2 bond and facilitates the rearrangement (Scheme 2). In this context, semi-empirical calculations at the AM1 level of theory predict that the gas-phase proton affinities of N3 in $2^{\prime}$-deoxycytidine- $5^{\prime}$-monophosphate and 2'-deoxycytidine-3'-monophosphate are higher than those of $O^{2}$ in the corresponding nucleotides by 2.5 and $3.9 \mathrm{kcal} / \mathrm{mol}$ [30]. On the other hand, high-level ab initio calculations with the inclusion of correlation effects at the Møller-Plesset level predicted that three atoms in neutral cytosine $\left(\mathrm{N} 1, \mathrm{~N} 3, \mathrm{O}^{2}\right)$ are susceptible to protonation all within a range of 1 $\mathrm{kcal} / \mathrm{mol}$ [31]. Furthermore, recent calculations suggested that the transition-state energies for proton migrations between $\mathrm{O}^{2}$ and $\mathrm{N} 3$ of 1-methylcytosine were much smaller than the threshold energy required for the major cleavage reactions discussed above [32]. Therefore, the protonated cytosine is expected to be present in the gas phase as a mixture of tautomers, whereas the N3-protonated tautomer can undergo the Dimroth-like rearrangement.

This Dimroth-like rearrangement, however, also makes it somewhat complicated to ascertain the origin of the $\mathrm{NH}_{3}$ loss. In analogy to the dissociation of uracil [18], the ammonia can be lost from N3 of cytosine. Alternatively, ammonia can be originated from the $N^{4}$ nitrogen. In this regard, the percentage of the product resulting from Dimroth-like rearrangement can be estimated to be $\sim 25 \%$ from the relative abundances of product ions emanating from the loss of HNCO and $\mathrm{H}^{15} \mathrm{NCO}$ (i.e., ions of $m / z 71$ and 70 , Figure 1e). On the other hand, $\sim 40 \%$ of the lost ammonia does not bear the ${ }^{15} \mathrm{~N}$ label (Figure 1e). Therefore, Dimroth-like rearrangement cannot account completely for the elimination of unlabeled $\mathrm{NH}_{3}$ from $\left[1,3-{ }^{15} \mathrm{~N}\right]$ cytosine; a small fraction of the ammonia, therefore, must be lost from $N^{4}$.

Further fragmentation of the most abundant ion $(\mathrm{m} / \mathrm{z}$ 95, which is originated from the loss of $\mathrm{NH}_{3}$ from cytosine) in $\mathrm{MS}^{3}$ of $\mathrm{dC}$ yields abundant product ions of $m / z 68$ and 67 , which are attributed to the losses of HCN 

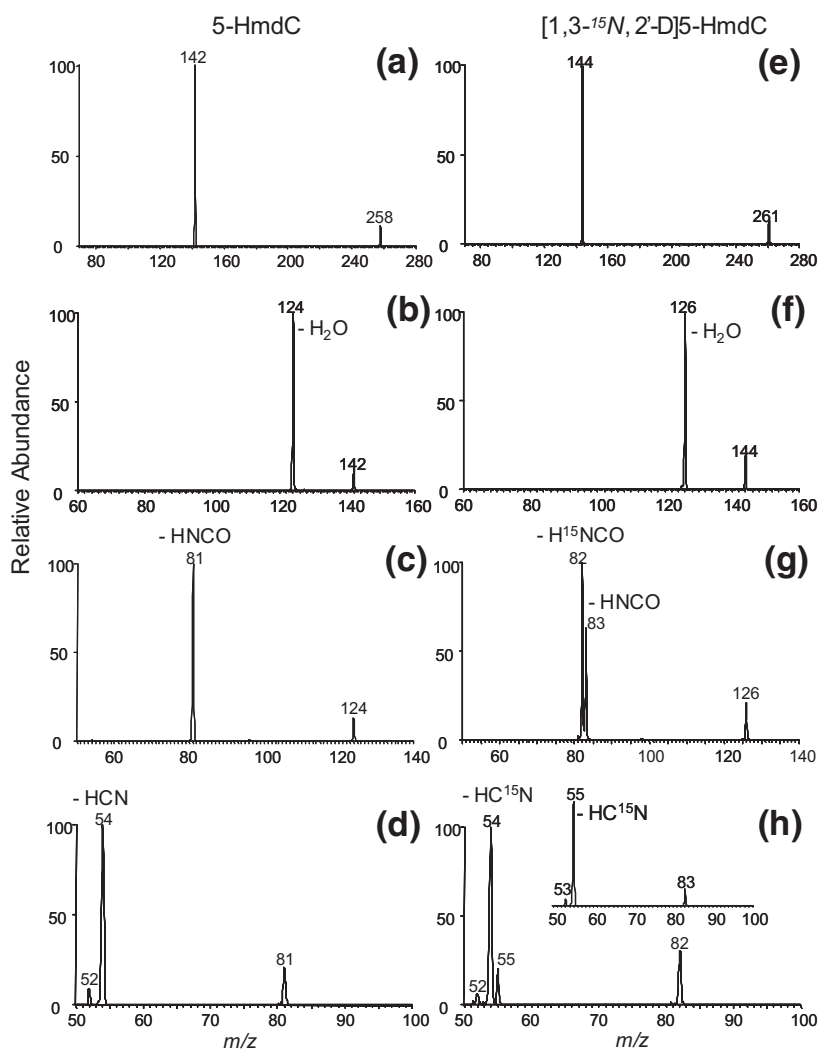

Figure 2. Mass spectra of $5-\mathrm{HmdC}$ (left) and $\left[1,3-{ }^{15} N, 2^{\prime}-\mathrm{D}\right] 5-$ HmdC (right): Product-ion spectra of the $\left[\mathrm{M}+\mathrm{H}^{+}\right.$ions of 5-HmdC (a) and $\left[1,3-{ }^{15} \mathrm{~N}, 2^{\prime}-\mathrm{D}\right] 5-\mathrm{HmdC}(\mathbf{e})$; product-ion spectra of the ions of $m / z 142$ and $144\left(\mathrm{MS}^{3}\right)$ observed in (a) and (e) are shown in (b) and (f), respectively; product-ion spectra of the ions of $\mathrm{m} / \mathrm{z}$ 124 and $126\left(\mathrm{MS}^{4}\right)$ observed in (b) and (f) are shown in (c) and (g), respectively; product-ion spectra of the ions of $m / z 81$ and $83\left(\mathrm{MS}^{5}\right.$ ) observed in (c) and (g) are shown in (d) and (h), respectively. Product-ion spectrum of the ion of $m / z 82\left(\mathrm{MS}^{5}\right)$ found in $(\mathrm{g})$ is shown as an inset in (h).

and $\mathrm{CO}$, respectively. The elimination of $\mathrm{HCN}$ involves primarily N1 nitrogen, as supported by the fact that the loss of $\mathrm{HC}^{15} \mathrm{~N}$, but not HCN, was observed in the $\mathrm{MS}^{4}$ of the ion of $\mathrm{m} / \mathrm{z} 96$ for $\left[1,3-{ }^{15} \mathrm{~N}\right]$ cytosine (Figure 1f).

In this context, it is worth noting that recent ab initio calculations predicted that, at an energetic point of view, the $43 \mathrm{Da}$ neutral loss found for protonated 1-methylcytosine is more likely to be an $\mathrm{HO}-\mathrm{C} \equiv \mathrm{N}$ moiety rather than an $\mathrm{HN}-\mathrm{C}=\mathrm{O}(\mathrm{HNCO})$ component

(a)

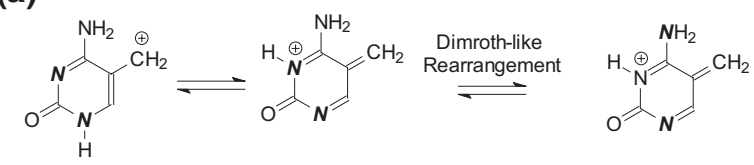

(b)

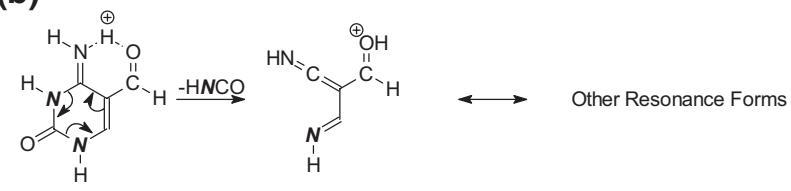

Scheme 3

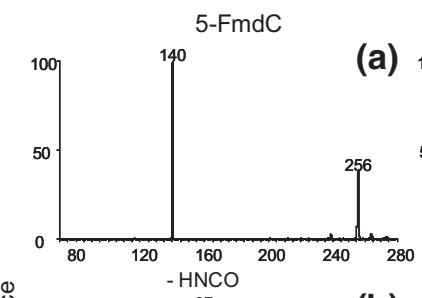

(a) $\begin{aligned} & 100 \\ & \end{aligned}$

$\left[1,3-15 N, 2^{\prime}-\mathrm{D}\right] 5-\mathrm{FmdC}$
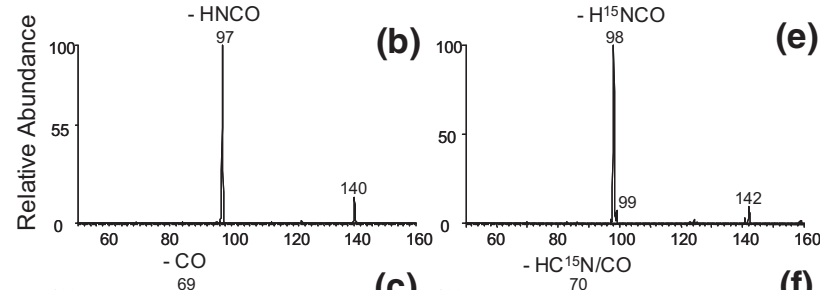

(e)
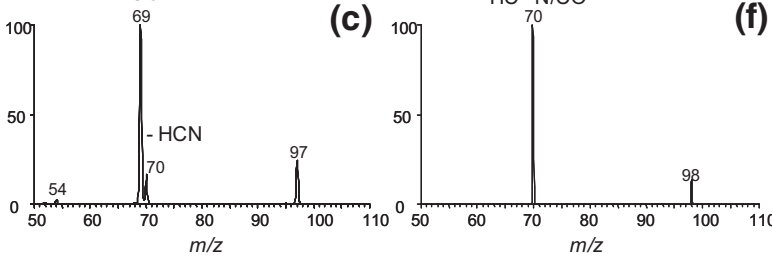

Figure 3. Mass spectra of 5-FmdC (left) and $\left[1,33^{15} N, 2^{\prime}-D\right] 5-$ FmdC (right): Product-ion spectra of the $[\mathrm{M}+\mathrm{H}]^{+}$ions of 5 -FmdC

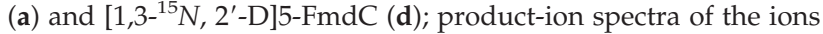
of $m / z 140$ and $142\left(\mathrm{MS}^{3}\right)$ observed in (a) and (d) are shown in (b) and (e), respectively; product-ion spectra of the ions of $\mathrm{m} / \mathrm{z} 97$ and $98\left(\mathrm{MS}^{4}\right)$ observed in (b) and (e) are shown in (c) and (f), respectively.

[32]. In that study, the authors only considered the dissociation pathway that is initiated from the cleavage of the N1-C2 bond. In this context, our experimental observation of the Dimroth-like rearrangement, however, supports that the cleavage of the protonated cytosine ring may also begin with the rupture of the $\mathrm{C} 2-\mathrm{N} 3$ bond. Moreover, the thermodynamic parameters for the cleavage pathways of protonated cytosine may differ from those of protonated 1-methylcytosine. Thus, it remains unclear what the identity is for the 43-Da neutral component. For convenience, we still refer to this as the HNCO component.

\section{5-Hydroxymethyl-2'-Deoxycytidine (5-HmdC)}

The collisional activation of the $[\mathrm{M}+\mathrm{H}]^{+}$ion of 5 -HmdC again leads to the facile cleavage of the glycosidic bond (Figure 2a). Further fragmentation of the protonated 5- $\mathrm{HmC}$ results in the predominant loss of an $\mathrm{H}_{2} \mathrm{O}$ molecule (Figure $2 \mathrm{~b}$ ), and the resulting product ion can readily eliminate an $\mathrm{HNCO}$ component upon further collisional activation $\left(\mathrm{MS}^{4}\right.$, Figure $\left.2 \mathrm{c}\right)$. In this regard, we again observed the losses of both $\mathrm{HNCO}(\mathrm{m} / \mathrm{z}$ 83) and $\mathrm{H}^{15} \mathrm{NCO}(\mathrm{m} / \mathrm{z} 82$, Figure $2 \mathrm{~g})$ from the [M $\left.\mathrm{H}_{2} \mathrm{O}\right]$ ion of $\left[1,3-{ }^{15} \mathrm{~N}\right] 5-\mathrm{HmC}$, which can be attributed to the similar Dimroth-like rearrangement as observed above for $\mathrm{dC}$ (Scheme 3a). From the relative abundances of these two ions we may estimate that $\sim 40 \%$ of the ion of $\mathrm{m} / \mathrm{z} 124$ has undergone such rearrangement, which is higher than what we found for the protonated dC. Further collisional activation of the ion of $\mathrm{m} / \mathrm{z} 81$ 


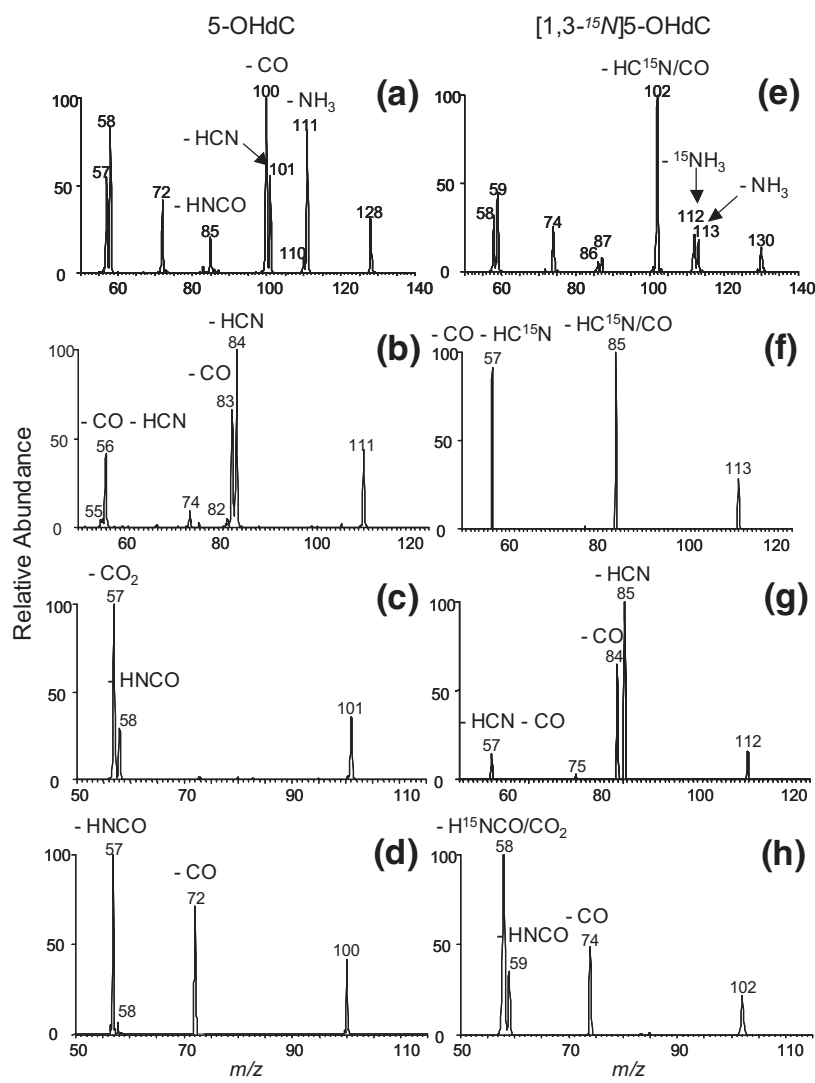

Figure 4. Mass spectra of 5-OHC (left) and $\left[1,3-{ }^{15} \mathrm{~N}\right] 5-\mathrm{OHC}$ (right): Product-ion spectra of the $[\mathrm{M}+\mathrm{H}]^{+}$ions of 5-OHC (a) and $\left[1,3-{ }^{15} \mathrm{~N}\right] 5-\mathrm{OHC}(\mathbf{e})$; product-ion spectra of the ions of $\mathrm{m} / \mathrm{z} 111,101$, and $100\left(\mathrm{MS}^{3}\right)$ observed in (a) are shown in (b), (c), and (d), respectively; product-ion spectra of the ions of $\mathrm{m} / \mathrm{z} 113,112$, and $102\left(\mathrm{MS}^{3}\right)$ observed in (b) are shown in $(\mathbf{f}),(\mathrm{g})$, and $(\mathbf{h})$, respectively.

$\left(\mathrm{MS}^{5}\right.$, Figure 2d) can lead to the facile elimination of an $\mathrm{HCN}$, and comparison of the $\mathrm{MS}^{5}$ shown in Figure $2 \mathrm{~d}$ and $h$ allows us to conclude that $\mathrm{HCN}$ is again most likely lost from N1.

The failure in observing the loss of $\mathrm{NH}_{3}$ from 5hydroxymethylcytosine $(5-\mathrm{HmC})$ is in sharp contrast with our observations for the unmodified cytosine, which might be attributed to the fact that, with the intermediate resulting from water loss (Scheme 3a), it is difficult to transfer three hydrogen atoms to the N3 position to render the ammonia loss.

\section{5-Formyl-2'-Deoxycytidine}

HNCO elimination is the dominant path for the dissociation of protonated 5-formylcytosine (5-FmC). Different from what we observed for the labeled cytosine and $5-\mathrm{HmC}$, collisional activation of the protonated [1,3$\left.{ }^{15} \mathrm{~N}\right]-5$-FmC leads to the formation of a dominant product ion of $\mathrm{m} / \mathrm{z} 98$, which is attributed to the elimination of $\mathrm{H}^{15} \mathrm{NCO}$ (Figure 3e). The ion emanating from the neutral loss of unlabeled HNCO (i.e., the ion of $\mathrm{m} / \mathrm{z} 99$ ) is, however, of very low abundance (Figure 3e). These results demonstrate that the Dimroth-like rearrange- ment was largely prohibited for the protonated 5-FmC and RDA reaction and became the most favorable dissociation pathway. This is reasonable on the grounds that the Dimroth-like rearrangement necessitates the protonation of N3, whereas the presence of the 5-formyl group renders the protonation of N3 most unlikely. In this regard, intramolecular hydrogen bonding leads to the facile protonation on the exocyclic 5-carbonyl group (Scheme $3 b$ ). The difficulty in protonating N3 also prevents the elimination of $\mathrm{NH}_{3}$ from the $[\mathrm{M}+\mathrm{H}]^{+}$ion of 5-FmC.

Further breaking down of the ion of $\mathrm{m} / \mathrm{z} 97\left(\mathrm{MS}^{4}\right)$ results in the facile loss of $\mathrm{CO}$, though the expulsion of $\mathrm{HCN}$ also constitutes a minor fragmentation pathway (Figure 3c). Corresponding fragmentation of the ion of $\mathrm{m} / \mathrm{z} 98$ demonstrates the loss of only $\mathrm{HC}^{15} \mathrm{~N}$, supporting that $\mathrm{HCN}$ is selectively eliminated from the N1 position (Figure 3f).

\section{5-Hydroxy-2'-Deoxycytidine}

The fragmentation of 5-OHdC again results in the facile formation of the protonated ion of the nucleobase (data not shown). The further breaking down of the 5hydroxycytosine (5-OHC) is much more complicated than those of other cytosine derivatives (Figure 4). In this regard, four major dissociation pathways were
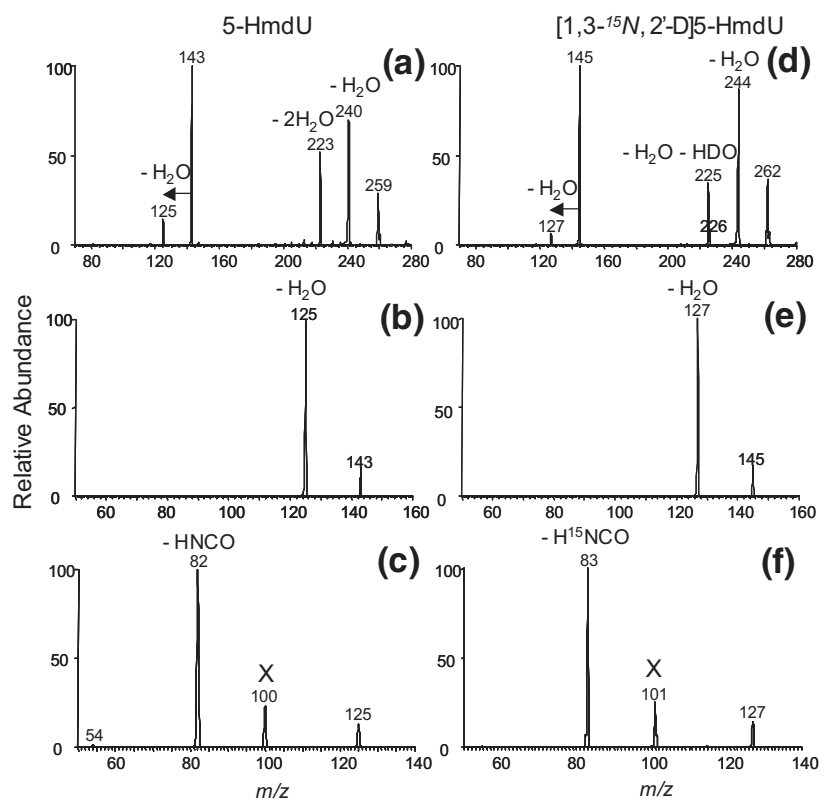

Figure 5. Mass spectra of $5-\mathrm{HmdU}$ (left) and $\left[1,3-{ }^{15} N, 2^{\prime}-\mathrm{D}\right] 5-$ HmdU (right): Product-ion spectra of the $[\mathrm{M}+\mathrm{H}]^{+}$ions of 5-HmdU (a) and $\left[1,3-{ }^{15} \mathrm{~N}, 2^{\prime}-\mathrm{D}\right] 5-\mathrm{HmdU}$ (d); product-ion spectra of the ions of $\mathrm{m} / \mathrm{z} 143$ and $145\left(\mathrm{MS}^{3}\right)$ observed in (a) and (d) are shown in (b) and (e), respectively; product-ion spectra of the ions of $\mathrm{m} / \mathrm{z} 125$ and $127\left(\mathrm{MS}^{3}\right)$ observed in (b) and (e) are shown in (c) and (f), respectively. The origins of the ions of $\mathrm{m} / \mathrm{z} 100$ and 101 (labeled with an " $X$ ") in (c) and (f), respectively, could be attributed to the ion-molecule reactions in the mass spectrometer (i.e., due to the addition of a water molecule, which is present in the ion trap, to the ion of $m / z 82$ or 83 ). 


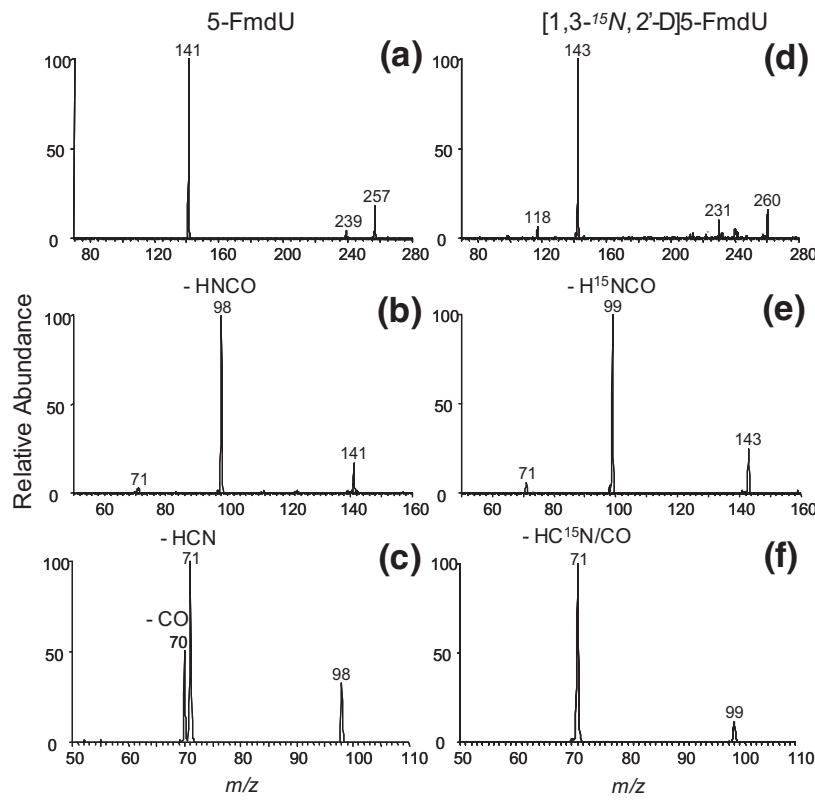

Figure 6. Mass spectra of 5-FmdU (left) and $\left[1,3-{ }^{15} N, 2^{\prime}-D\right] 5-$ FmdU (right): Product-ion spectra of the $[\mathrm{M}+\mathrm{H}]^{+}$ions of

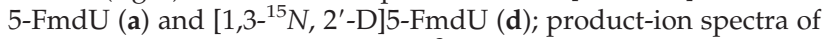
the ions of $\mathrm{m} / \mathrm{z} 141$ and $143\left(\mathrm{MS}^{3}\right)$ observed in (a) and (d) are shown in (b) and (e), respectively; product-ion spectra of the ions of $\mathrm{m} / \mathrm{z} 98$ and 99 observed in (b) and (e) are shown in (c) and (f), respectively.

observed for the protonated 5-OHC: (1) Loss of $\mathrm{NH}_{3}$ $(\mathrm{m} / \mathrm{z} 111)$ followed by the elimination of $\mathrm{HCN}(\mathrm{m} / \mathrm{z} 84)$, $\mathrm{CO}(\mathrm{m} / \mathrm{z} 83)$, or both $(\mathrm{m} / \mathrm{z} 56)$. It is worth noting that the neutral loss of HCN carries exclusively the ${ }^{15} \mathrm{~N}$ label, suggesting that, similar to what we found for the other cytosine derivatives, the nitrogen atom in $\mathrm{HCN}$ most likely originated from the N1 position of cytosine (Figure $4 \mathrm{a}, \mathrm{b}, \mathrm{f}$, and g). (2) Loss of $\mathrm{HCN}(\mathrm{m} / \mathrm{z}$ 101) followed by expulsion of $\mathrm{HNCO}(\mathrm{m} / \mathrm{z} 58)$ or $\mathrm{CO}_{2}(\mathrm{~m} / \mathrm{z}$ 57, Figure $4 \mathrm{c}$ and h). (3) Elimination of $\mathrm{CO}(\mathrm{m} / \mathrm{z}$ 100) with further neutral losses of $\mathrm{CO}$ and HNCO to form product ions of $\mathrm{m} / \mathrm{z} 72$ and 57 (Figure $4 \mathrm{~d}$ and h). The elimination of both $\mathrm{HNCO}$ and $\mathrm{H}^{15} \mathrm{NCO}$ from the labeled precursor in pathways (2) and (3) again supports that Dimroth-like rearrangement occurs for the protonated 5-OHC. The extent of Dimroth-like rearrangement, as judged from the relative abundances of the pairs of ions resulting from HNCO loss, is similar to what was observed for the unmodified cytosine. (4) Elimination of HNCO $(\mathrm{m} / \mathrm{z}$ 85, Figure $4 \mathrm{a}$ and e). Other fragment ions, i.e., the ions of $m / z 72,58$, and 57 (Figure 4a) can be either product ions from direct neutral losses from parent ion $(\mathrm{m} / \mathrm{z} 128)$ or secondary ions from other product ions described above.

\section{5-Hydroxymethyl-2'-Deoxyuridine and 5-Formyl-2'-Deoxyuridine}

We next acquired multi-stage MS data for the corresponding dU derivatives. Since the fragmentation of the protonated ions of uracil and 5-hydroxyuracil have been reported by Nelson and McCloskey [18], here we focus our discussion on the fragmentation of 5hydroxymethyluracil (5-HmU) and 5-formyluracil (5FmU). It turned out that the pathways for the dissociation of these two nucleobases parallel largely our observations with the corresponding cytosine derivatives. In this respect, we found that the loss of $\mathrm{NH}_{3}$ is prohibited for the protonated ions of both $5-\mathrm{HmU}$ and 5-FmU (Figure 5 and Figure 6). In addition, we again observed facile loss of an $\mathrm{H}_{2} \mathrm{O}$ molecule from the protonated $5-\mathrm{HmU}\left(\mathrm{MS}^{3}\right.$, Figure $5 \mathrm{~b}$ and e) and the resulting product ion can readily lose an $\mathrm{HNCO}$ component upon further fragmentation (MS ${ }^{4}$, Figure $5 \mathrm{c}$ and f). The collisional activation of the $[\mathrm{M}+\mathrm{H}]^{+}$ions of 5 -FmU and $\left[1,3-{ }^{15} \mathrm{~N}\right] 5-\mathrm{FmU}$ results in the predominant loss of an $\mathrm{HNCO} / \mathrm{H}^{15} \mathrm{NCO}$ molecule $\left(\mathrm{MS}^{3}\right.$, Figure $6 \mathrm{~b}$ and e) and the resulting product ion can undergo a facile elimination of $\mathrm{HCN} / \mathrm{HC}^{15} \mathrm{~N}$ or $\mathrm{CO}$ molecule $\left(\mathrm{MS}^{4}\right.$, Figure $6 \mathrm{c}$ and $\left.\mathrm{f}\right)$. The failure in observing the loss of an $\mathrm{NH}_{3}$ molecule can be rationalized by the same principles as discussed for the corresponding cytosine derivatives (vide supra).

\section{Conclusions}

In this study, the fragmentation pathways of the protonated ions of $\mathrm{dC}, \mathrm{dU}$, and their oxidatively damaged derivatives were investigated by isotope labeling and $\mathrm{MS}^{\mathrm{n}}$. The initial dissociation of the protonated ions of most 2'-deoxynucleosides discussed in this paper involves the rupture of the weak $\mathrm{N}$-glycosidic bond to give the protonated nucleobases. In addition, we found that Dimroth-like rearrangement, which has been observed for adenosine, can occur for the protonated ions of cytosine, 5-hydroxymethylcytosine and 5hydroxycytosine, but not for the protonated 5-formylcytosine, in the gas phase, leading to the exchange of nitrogen at $\mathrm{N} 3$ and $N^{4}$ positions. Therefore, identification for the modifications being on $\mathrm{N}^{4}$ or N3 of cytosine by MS/MS should be proceeded with caution.

Another interesting discovery in this study is that no ammonia loss was observed for either the 5-hydroxymethyl- or the 5-formyl-substituted cytosine and uracil derivatives. This could be attributed to either the drastically decreased propensity in protonating the N3 of the modified pyrimidine base or the reduced tendency for hydrogen to be transferred to the nitrogen atom for ammonia loss.

It has been previously reported that the nucleosidederived protonated nucleobase (i.e., the $[\mathrm{B}+\mathrm{H}]^{+}$ion), gives rise to indistinguishable tandem mass spectrum from the $[\mathrm{M}+\mathrm{H}]^{+}$ion formed from the corresponding nucleobase $[18,33]$. Therefore, the fragmentation results discussed here, which were obtained for the protonated nucleobase ions from the fragmentation of the corresponding 2'-deoxynucleosides, can generally be extended to nucleobases from either DNA or RNA. In many cases, mass spectrometry is the only viable method for the identification of unknown nucleosides 
due to the quantity limitation and complexity of samples to be analyzed [15]. The results reported here, together with seminal work from the McCloskey laboratory [17-19], can serve as the basis for elucidating the structures of novel modified nucleobases in RNA or DNA by MS/MS.

\section{Acknowledgments}

This work was supported by the National Institutes of Health (R01 CA96906)

\section{References}

1. Rozenski, J.; Crain, P. F.; McCloskey, J. A. The RNA modification database: 1999 update. Nucleic Acids Res. 1999, 27, 196-197.

2. Cooke, M. S.; Evans, M. D.; Dizdaroglu, M.; Lunec, J. Oxidative DNA damage: Mechanisms, mutation, and disease. FASEB J. 2003, 17, 11951214 .

3. Hofer, T.; Badouard, C.; Bajak, E.; Ravanat, J. L.; Mattsson, A.; Cotgreave, I. A. Hydrogen peroxide causes greater oxidation in cellular RNA than in DNA. Biol. Chem. 2005, 386, 333-337.

4. Urbonavicius, J.; Qian, O.; Durand, J. M. B.; Hagervall, T. G.; Bjork, G. R. Improvement of reading frame maintenance is a common function for several tRNA modifications. EMBO J. 2001, 20, 4863-4873.

5. Decatur, W. A.; Fournier, M. J. rRNA modifications and ribosome function. Trends. Biochem. Sci. 2002, 27, 344-351.

6. King, T. H.; Liu, B.; McCully, R. R.; Fournier, M. J. Ribosome structure and activity are altered in cells lacking snoRNPs that form pseudouridines in the peptidyl transferase center. Mol. Cell 2003, 11, 425-435.

7. Dizdaroglu, M. Mechanisms of oxidative DNA damage; lesions and their measurement. NATO ASI Ser., Ser. A 1999, 302, 67-87.

8. Evans, M. D.; Dizdaroglu, M.; Cooke, M. S. Oxidative DNA damage and disease: Induction, repair, and significance. Mutat. Res. 2004, 567, 1-61.

9. Finkel, T.; Holbrook, N. J. Oxidants, oxidative stress and the biology of ageing. Nature 2000, 408, 239-247.

10. Kammerer, B.; Frickenschmidt, A.; Muller, C. E.; Laufer, S.; Gleiter, C. H.; Liebich, H. Mass spectrometric identification of modified urinary nucleosides used as potential biomedical markers by LC-ITMS coupling. Anal. Bioanal. Chem. 2005, 382, 1017-1026.

11. Dudley, E.; Lemiere, F.; Van Dongen, W.; Langridge, J. I.; El-Sharkawi, S.; Games, D. E.; Esmans, E. L.; Newton, R. P. Analysis of urinary nucleosides. III. Identification of 5 -deoxycytidine in urine of a patient with head and neck cancer. Rapid Commun. Mass Spectrom. 2003, 17, 1132-1136.

12. Badouard, C.; Masuda, M.; Nishino, H.; Cadet, J.; Favier, A.; Ravanat, J. L. Detection of chlorinated DNA and RNA nucleosides by HPLC coupled to tandem mass spectrometry as potential biomarkers of inflammation. J. Chromatogr. B 2005, 827, 26-31.

13. Badouard, C.; Douki, T.; Faure, P.; Halimi, S.; Cadet, J.; Favier, A.; Ravanat, J.-L. DNA lesions as biomarkers of inflammation and oxida- tive stress: a preliminary evaluation. NATO Sci. Ser., Ser. I: Life and Behav. Sci. 2005, 367, 1-9.

14. Weimann, A.; Belling, D.; Poulsen, H. E. Quantification of 8-oxoguanine and guanine as the nucleobase, nucleoside, and deoxynucleoside forms in human urine by high-performance liquid chromatography-electrospray tandem mass spectrometry. Nucleic Acids Res. 2002, 30, e7.

15. Singh, R.; Farmer, P. B. Liquid chromatography-electrospray ionizationmass spectrometry: The future of DNA adduct detection. Carcinogenesis 2006, 27, 178-196.

16. Dizdaroglu, M.; Jaruga, P.; Birincioglu, M.; Rodriguez, H. Free radicalinduced damage to DNA: Mechanisms and measurement. Free Radical Biol. Med. 2002, 32, 1102-1115.

17. Nelson, C. C.; McCloskey, J. A. Collision-induced dissociation of adenine. J. Am. Chem. Soc. 1992, 114, 3661-3668.

18. Nelson, C. C.; McCloskey, J. A. Collision-induced dissociation of uracil and its derivatives. J. Am. Soc. Mass Spectrom. 1994, 5, 339-349.

19. Gregson, J. M.; McCloskey, J. A. Collision-induced dissociation of protonated guanine. Int. J. Mass Spectrom. 1997, 165, 475-485.

20. LaFrancois, C. J.; Fujimoto, J.; Sowers, L. C. Synthesis and characterization of isotopically enriched pyrimidine deoxynucleoside oxidation damage products. Chem. Res. Toxicol. 1998, 11, 75-83.

21. Hong, H.; Cao, H.; Wang, Y.; Wang, Y. Identification and quantification of a guanine-thymine intrastrand cross-link lesion induced by $\mathrm{Cu}(\mathrm{II}) /$ $\mathrm{H}_{2} \mathrm{O}_{2}$ /ascorbate. Chem. Res. Toxicol. 2006, 19, 614-621.

22. Fujii, T.; Itaya, T. The Dimroth rearrangement in the adenine series: A review updated. Heterocycles 1998, 48, 359-390.

23. El Ashry, E. S. H.; El Kilany, Y.; Rashed, N.; Assafir, H. Dimroth rearrangement: Translocation of heteroatoms in heterocyclic rings and its role in ring transformations of heterocycles. Adv. Heterocycles Chem. 2000, 75, 79-165.

24. Engel, J. D. Mechanism of the Dimroth rearrangement in adenosine. Biochem. Biophys. Res. Commun. 1975, 64, 581-586.

25. Turecek, F.; Chen, X. H. Protonated adenine: Tautomers, solvated clusters, and dissociation mechanisms. J. Am. Soc. Mass Spectrom. 2005, $16,1713-1726$.

26. Delia, T. J.; Olsen, M. J.; Bosworth Brown, G. Cytosine 3-N-oxide and its rearrangement on acetylation. J. Org. Chem. 1965, 30, 2766-2768.

27. Ueda, T.; Fox, J. J. Pyrimidines. IV. The interconversion of $N^{4}$ methylcytosine and 3-methylcytosine. J. Org. Chem. 1964, 29, 1770-1772.

28. Wempen, I.; Brown, G. B.; Ueda, T.; Fox, J. J. Pyrimidines. V. Rearrangement of cytosine amino- ${ }^{15} \mathrm{~N}$ and a preparation of uracil- ${ }^{15} \mathrm{~N} 3$. Biochemistry 1965, 4, 54-57.

29. Sako, M.; Kawada, H. A new and efficient synthetic method for N-15(3)-labeled cytosine nucleosides: Dimroth rearrangement of cytidine N-3-oxides. J. Org. Chem. 2004, 69, 8148-8150.

30. Green-Church, K. B.; Limbach, P. A. Mononucleotide gas-phase proton affinities as determined by the kinetic method. J. Am. Soc. Mass Spectrom. 2000, 11, 24-32.

31. Colominas, C.; Luque, F. J.; Orozco, M. Tautomerism and protonation of guanine and cytosine. Implications in the formation of hydrogenbonded complexes. J. Am. Chem. Soc. 1996, 118, 6811-6821.

32. Yao, C.; Cuadrado-Peinado, M. L.; Polasek, M.; Turecek, F. Gas-phase tautomers of protonated 1-methylcytosine. Preparation, energetics, and dissociation mechanisms. J. Mass Spectrom. 2005, 40, 1417-1428.

33. Crain, P. F. Mass-spectrometric techniques in nucleic-acid research. Mass Spectrom. Rev. 1990, 9, 505-554. 